\title{
Equilibrium desorption isotherms of water, ethanol, ethyl acetate, and toluene on a sodium smectite clay
}

\author{
Pascal Clausen - Marco Signorelli - Andreas Schreiber • \\ Eric Hughes · Christopher J. G. Plummer - Dimitrios Fessas • \\ Alberto Schiraldi · Jan-Anders E. Månson
}

Received: 10 December 2008/Accepted: 7 May 2009/Published online: 9 July 2009

(c) Akadémiai Kiadó, Budapest, Hungary 2009

\begin{abstract}
Desorption isotherms for water, ethanol, ethyl acetate and toluene from a sodium smectite clay have been determined by both dynamic vapor sorption (DVS) measurements and Knudsen thermogravimetry (KTGA), at the exception of toluene that was measured only by the DVS method. The results obtained using these two methods were in satisfactory agreement, providing reliable insight into the desorption process, with certain lack of precision for ethyl acetate. The observed desorption behaviour suggests a liquid like phase at high volatile load, and a sorbed state in which molecules interact with the counter ions, at low volatile contents. However, the isotherms for water determined at various temperatures nearly superposed when plotted as a function of water activity, indicating the strength of the interactions in the clay-water system to remain of the same order of magnitude as that in bulk water, consistent with previous ab initio calculations.
\end{abstract}

P. Clausen $(\bowtie)$ C C. J. G. Plummer · J.-A. E. Månson

Laboratoire de Technologie des Composites et Polymères

(LTC), Ecole Polytechnique Fédérale de Lausanne (EPFL),

1015 Lausanne, Switzerland

e-mail: pascal.clausen@epfl.ch

P. Clausen - E. Hughes

Nestlé Research Center, Vers-Chez-Les-Blanc,

1000 Lausanne 26, Switzerland

M. Signorelli · D. Fessas · A. Schiraldi

DiSTAM, Università di Milano, Via Celoria, 2,

20133 Milan, Italy

A. Schreiber

POROTEC, GmbH, 65719 Hofheim, Germany
Keywords Clay - Dynamic vapour sorption - Ethanol · Ethyl acetate $\cdot$ Knudsen thermogravimetry $\cdot$ Smectite Sorption isotherm - Toluene - Water

\section{Introduction}

Smectites are an important class of clay minerals whose surface properties are of interest in an increasingly wide range of applications [1], from construction materials to catalysts. They belong to the structural family referred to as the $2: 1$ phyllosilicates, characterized by a two-dimensional crystal lattice in which a central octahedral sheet of alumina or magnesia is fused to two external silica tetrahedral sheets such that the oxygen ions of the octahedral sheet are shared with those of the tetrahedral sheets. The total thickness of the resulting layers is about $1 \mathrm{~nm}$, and their lateral dimensions vary from $300 \AA$ to several microns. Isomorphic substitution within the layers (for example, $\mathrm{Mg}^{2+}$ or $\mathrm{Fe}^{2+}$ for $\mathrm{Al}^{3+}$, or $\mathrm{Li}^{+}$for $\mathrm{Mg}^{2+}$ ) and vacancies generate net negative charges. These are counterbalanced by alkali or alkaline earth cations present between the layers, and the layers are hence able to form stable stacks with a well-defined interlayer spacing, which further aggregate to form the clay. Depending on their polarity and the type of clay counter ion, certain molecules may penetrate the interlayer galleries, resulting in significant swelling [2-5]. Such molecules range from low molar mass compounds, such as water [6,7], volatile organic species [8-13], and non-volatile low molecular mass species [14, 15], to macromolecules [16-18].

The sorption kinetics of volatile molecules on smectite clays, which are important for many applications, depends on the partition between the molecules sorbed in the clay and those in the gas phase [19]. This may be characterized 
by the sorption isotherm, i.e. the amount of volatiles sorbed as a function of the partial vapor pressure of the volatiles above the adsorbent, which is in turn linked to the thermodynamic activity of the volatile in the condensed phase. The sorption isotherm often shows significant hysteresis, because adsorption and desorption may proceed differently, an effect that is well known for the adsorption/ desorption of water on smectite clays [20], and is particularly marked for sodium smectites [21]. The desorption isotherm allows evaluation of the release kinetics of volatiles from smectite clays [19]. Comparison of desorption isotherms for different volatiles is therefore expected to provide further insight into their relative release rates from the clay.

The present work addresses the desorption isotherms of water, ethanol, ethyl acetate and toluene from smectite clays. To the authors' knowledge, there are currently no data in the literature for the equilibrium desorption isotherms of ethanol, ethyl acetate or toluene from smectites, although some data are available for the adsorption isotherm of ethanol. Ethanol is able to cover completely the smectite surface at high enough vapor pressures, resulting in an increase in the layer spacing [8]. Liquid toluene is also known to enter the interlayer galleries, but is adsorbed mainly at the external surface [9].

Lattice models from statistical mechanics show that the strength of the interactions between volatile molecules and the surface of an adsorbent is crucial for the corresponding equilibrium sorption isotherm [22-26]. Cation-dipole interactions have been suggested to govern the interactions between polar molecules and clay counter ions [10, 11, 27], whereas cation $-\pi$ interactions appear to be important for the interactions between aromatic molecules and clay [12, $28,29]$. Because the dipole moment of water is greater than that of ethanol, one expects stronger binding between clay and water than between clay and ethanol [30]. However, observations of the release of water and ethanol from Na-, $\mathrm{Ca}$ - and $\mathrm{Mg}$-smectites as the temperature is increased indicate ethanol to bind to the clay more strongly than water [11]. The binding energies of water, ethanol, ethyl acetate, pyridine and toluene with the counter ion of a sodium smectite clay have been determined by ab initio calculations [31]. They were found to be in the order: pyridine $>$ ethyl acetate $>$ ethanol $>$ water $>$ toluene. The differences in the binding energies of water, ethanol, ethyl acetate and pyridine were accounted for in terms of the local interactions between the sodium counter ion and the electronegative atom present in each molecule, as opposed to cation-dipole interactions, and the ionization potential was found to be strongly correlated with the binding energy. For toluene, on the other hand, the binding energy was found to be of the order of that associated with a hydrogen bond. On the basis of these results, one therefore expects the activity of volatiles at low coverage to be in the order: ethyl acetate $<$ ethanol $<$ water $<$ toluene.

The desorption isotherms were obtained using two different methods, namely, dynamic vapour sorption (DVS) and Knudsen thermogravimetry (KTGA).

\section{Experimental}

\section{Materials}

The smectite clay used in the present work was a Kunipia F, raw sodium montmorillonite clay from Kunimine, Japan. The model volatiles used for the experiments were water (for chromatography, Merck), ethanol (absolute GR for analysis, Merck), toluene (GR for analysis, Merck) and ethyl acetate (GR for analysis, Merck).

\section{Desorption isotherms by dynamic vapour sorption}

A DVS-2000 instrument from SMS (Surface Measurements Systems, UK) was used to measure the desorption isotherm of water from the clay. Prior to experiments the clay was dried at $0 \%$ RH. Dry nitrogen gas with a purity of $99.995 \%$ was used as the carrier gas. The clay was then equilibrated at relative humidities from 95 to $0 \% \mathrm{RH}$ in $5 \% \mathrm{RH}$ steps by adjusting the ratio of dry and saturated gas flows, these latter being calibrated with $\mathrm{NaCl}, \mathrm{MgCl}_{2}$, and $\mathrm{LiCl}$ salt solutions.

The clay was assumed to be equilibrated when its variation in mass remained for 10 minutes below $0.0002 \% / \mathrm{min}$ of the dry class mass. About $50 \mathrm{mg}$ of material was used for each measurement. The residual water content after DVS drying determined to be $0.73 \mathrm{wt} \%$ by heating the samples to $200{ }^{\circ} \mathrm{C}$. This was taken into account in the calculations of the water contents.

The desorption isotherms of ethanol, ethyl acetate and toluene were determined with the DVS-advantage instrument (Surface Measurements Systems, UK) adapted for use with organic volatiles. The partial pressure of the vapor was controlled by adjusting the flow ratio of saturated and dry carrier gas (dried air, cleaned with an adsorption filter (pure gas products) $\mathrm{H}_{2} \mathrm{O}<15 \mathrm{ppb}$ ).

The vapor concentration was measured with a dew point analyzer. The clay was equilibrated at relative activities from about $90 \%$ to $0 \%$. The clay was assumed to be equilibrated when the variation of the as mass did not exceed $0.001 \%$ of the actual mass per minute over $10 \mathrm{~min}$. About 15-30 mg samples were used.

\section{Desorption isotherms by Knudsen thermogravimetry}

Desorption isotherms were also measured by KTGA using a combined thermobalance-differential scanning calorimetry 
Setaram (France) TG-DSC111. When the standard pans of the balance are replaced with Knudsen cells, which communicate with a low external pressure $p_{\text {ext }}\left(10^{-4} \mathrm{~Pa}\right)$ through a $20 \mu \mathrm{m}$ orifice, an isothermal drying process can be triggered by means of a turbomolecular pump. Under these conditions, the driving force for the removal of volatile molecules from the cell is the drop of volatile partial pressure, $p$, across the orifice. Since the $p_{e x t}$ is always at least twoorders of magnitude lower than the partial pressure $p_{\text {int }}$ of the volatile inside the cell, the loss rate of volatiles $d m_{v} / d t$ is essentially proportional to $p_{i n t}$, i.e.:

$\frac{d m}{d t}=K\left(p_{\text {int }}-p_{\text {ext }}\right) \cong K p_{\text {int }}$

where $K$ is constant for a given gas escaping through a Knudsen orifice of a given geometrical size and at a given temperature. The ratio between the mass loss rate $\left(d m_{v} / d t\right)$ from a given material and the mass loss rate $\left(d m_{v} / d t\right) *$ from the pure volatile liquid, at the same temperature and with the same Knudsen cell, gives the evolution of the relative vapour pressure, which is equivalent to the thermodynamic activity of the volatile in the material under consideration, $a_{v}$.

$\frac{\frac{d m}{d t}}{\left(\frac{d m}{d t}\right)^{*}} \cong \frac{K p_{\text {int }}}{K p_{\text {int }}^{*}}=\frac{p_{\text {int }}}{p_{\text {int }}^{*}}=a_{v}$

where $p_{\text {int }}^{*}$ is the saturated vapor pressure of the pure volatile inside the cell. Prior to measurements, the clay was dried at $50{ }^{\circ} \mathrm{C}$ with a $\mathrm{P}_{2} \mathrm{O}_{5}$ adsorbent under vacuum, and then mixed with the volatile liquid to form a slurry.

Determination of water content at $43 \% \mathrm{RH}$ by saturated salt solutions

In addition to the DVS and KTGA measurements, the water content in the clay at $43 \% \mathrm{RH}$ and $25^{\circ} \mathrm{C}$ was measured using saturated solutions. The clay was equilibrated at $97 \% \mathrm{RH}$ and $25{ }^{\circ} \mathrm{C}$ using a saturated solution of $\mathrm{K}_{2} \mathrm{SO}_{4}$. After one month, the clay was equilibrated for another month at $43 \% \mathrm{RH}$ using a saturated solution of $\mathrm{K}_{2} \mathrm{CO}_{3}$. The clay was then dried for 2 days at $50{ }^{\circ} \mathrm{C}$ with a $\mathrm{P}_{2} \mathrm{O}_{5}$ adsorbent under a vacuum of 70 Torr.

\section{Results}

Reproducibility of the equilibrium desorption isotherms measurements

\section{$D V S$}

The DVS equilibrium desorption isotherms for water (at $25^{\circ} \mathrm{C}$ ), and for ethanol, ethyl acetate and toluene (at $35^{\circ} \mathrm{C}$ ) are shown in Fig. 1, in which the data have been represented by plotting the mass fraction, $w_{f}$ (Eq. 3) versus $a_{v}$ (Eq. 4),

$w_{f}=\frac{m_{v}}{m_{c}}$

$a_{v}=\frac{p_{v}}{p_{v}^{*}}$

where $m_{v}$ and $m_{c}$ are the mass of adsorbed volatile and the clay dry mass, respectively, $p_{v}$ is the pressure of the volatile above the clay, and $p_{v}^{*}$ is the saturated vapour pressure of the pure volatile liquid at the same temperature.

The desorption isotherms of water and ethanol showed good reproducibility, but those of ethyl acetate and toluene were associated with $1-2 \%$ and $0.5 \%$ errors respectively. The desorption isotherm of water showed two distinct steps, whereas the ethanol, ethyl acetate and toluene desorption isotherms were more reminiscent of a Langmuir isotherm. The two step isotherm is generally associated with the hydration of the clay counter ion and the displacement of the clay layers, the interlayer spacing reaching values characteristic of a double solvation layer [3]. The lack of evidence for two steps in ethanol, ethyl acetate and toluene and the relatively low maximum amounts of sorbed volatile suggest that the counter ions were not fully solvated and the clay layers did not expand beyond the equivalent of monolayer coverage.

It is significant that the amount of water sorbed at $a_{\mathrm{v}}=0.95$ was about $30 \mathrm{wt} \%$, i.e. almost 3 times the amount of ethanol and ethyl acetate sorbed at the same $a_{\mathrm{v}}$. The maximum amount of sorbed toluene was even lower, i.e., about 10 times less than that of water. This may be attributed to the difficulty toluene has in migrating towards the clay interlayer galleries, its adsorption occurring mainly at the external surface [9]. The increase in adsorption observed at higher volatile loadings may be attributed to the filling of micropores by capillarity.

\section{KTGA}

The KTGA desorption isotherms for bulk water at 25 and $10{ }^{\circ} \mathrm{C}$, and bulk ethanol and ethyl acetate at $10{ }^{\circ} \mathrm{C}$, are given in Fig. 2. In these experiments the main uncertainty was associated with residual volatile in the clay at the end of each run. To determine the amount of residual volatile, the cell was heated to $70^{\circ} \mathrm{C}$. Satisfactory reproducibility was observed for water and ethanol, but the results for ethyl acetate showed more uncertainty. Two steps were again present in the desorption isotherms of water, but were less in evidence for the ethanol and ethyl acetate, consistent with the results from the DVS measurements. 
Fig. 1 DVS measurements of the desorption isotherms of the volatiles from smectite clay. The mass fraction of the volatiles $\mathrm{w}_{f}$ is plotted as a function of the volatile activity $a_{v}$ : a water (at $\left.25^{\circ} \mathrm{C}\right)$, b ethanol, c ethyl acetate, $\mathbf{d}$ toluene (all at $35{ }^{\circ} \mathrm{C}$ )
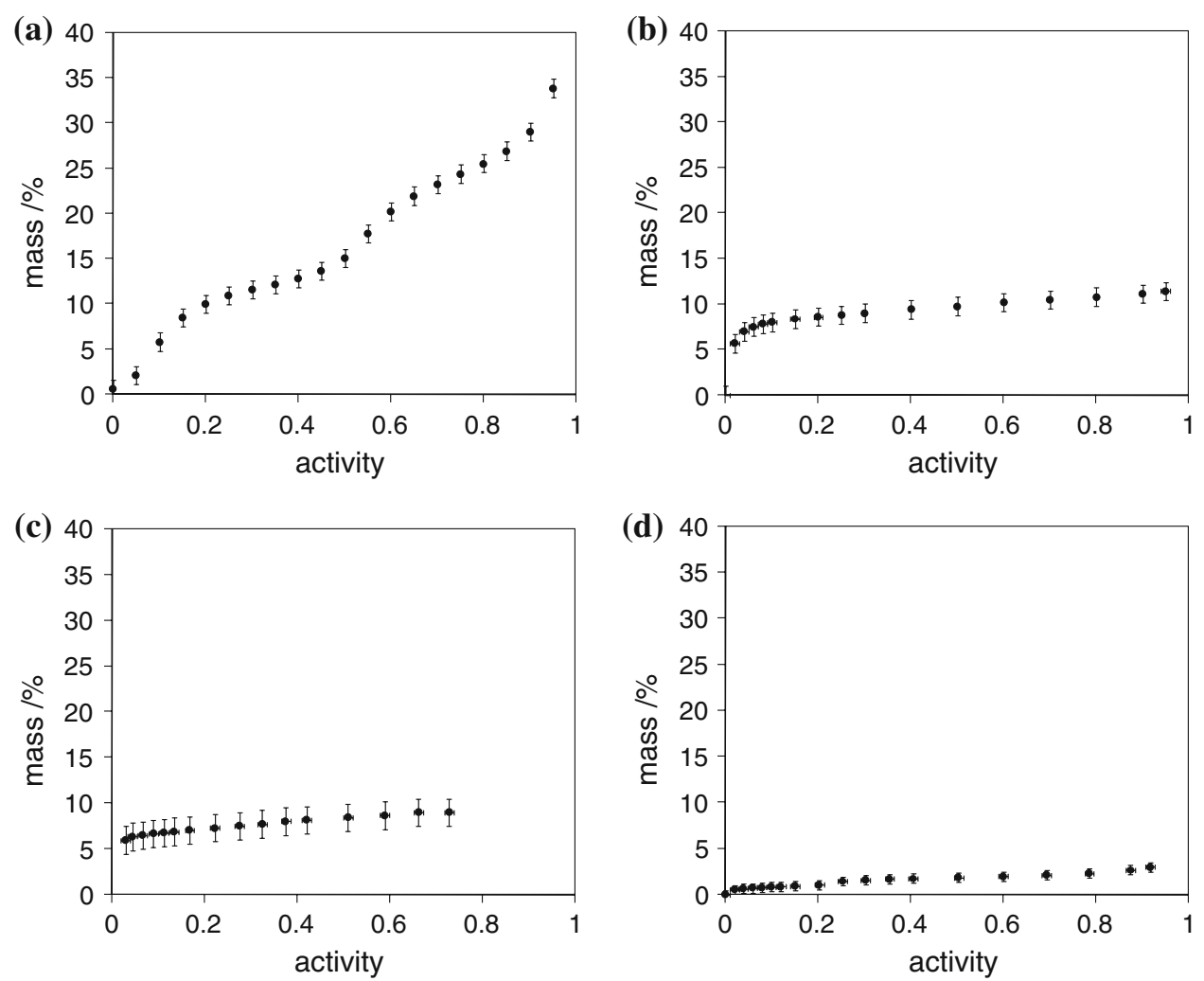

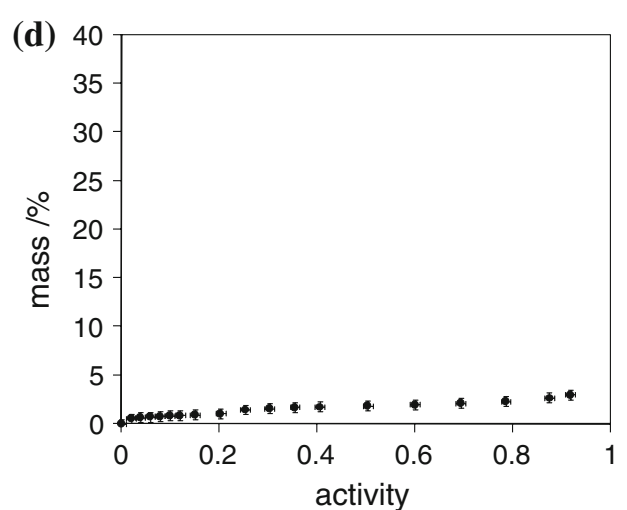

Comparison between the KTGA and DVS measurements for water

In the KTGA method, the data provide a continuous record of the desorption process, and the acquisition time for a complete desorption isotherm is about 10 times shorter than for the DVS method. However, the desorption isotherms could only be obtained at relatively low temperatures in the present case $\left(10^{\circ} \mathrm{C}\right)$, because the evaporation rates of water, ethanol and ethyl acetate was too rapid at higher temperatures, and the technique was not suitable for toluene because of the intrinsic limitations of the available Knudsen cells (O-ring sealing sensitive to toluene vapor). On the other hand data could only be obtained at relatively high temperatures by DVS, because equilibrium could not be reached at low temperatures over reasonable periods of time.

Both the KTGA and the DVS methods also have limitations at very low vapor pressures. In the case of DVS, low vapor pressures are difficult to control and measure owing to the limited accuracy of the flow control and the dew point analyzer. In the case of the KTGA method, the volatile cannot be fully removed from the sample at the measurement temperature, so that the evaluation of $m_{\mathrm{v}}$ requires additional quantification of the residual volatile.

Figure 3 shows the desorption isotherms of water obtained with the two methods at $25^{\circ} \mathrm{C}$. The two trends are in substantial agreement, the main discrepancies being observed in the ranges of $a_{\mathrm{v}}$ corresponding to large changes in slope, i.e. at very low and very high water contents, and at the transition between the two pseudo-plateaus. These discrepancies may be accounted for in terms of the dynamic nature of Knudsen desorption, which implies steady migration of the solvent towards the head space and then through the orifice of the Knudsen cell. The system requires a certain time to achieve the steady state characterized by Eq. 1. A slower suction rate, e.g., use of a narrower orifice, usually improves performance, but increases the measurement time. The Knudsen cell used in the present case was designed for foodstuffs [32] that necessitate relatively rapid measurements because of their tendency to degrade. The orifice size therefore represents a compromise between the suction rate and the experimental time, and hence the sensitivity to changes in the desorption rate. The differences between the Knudsen and DVS isotherms were nevertheless limited to around $2.4 \%$ in the range of most relevance for applications, i.e. for $\mathrm{RH}$ of the order $45 \%$, in which the results from DVS were also consistent with those obtained from saturated salt solutions.

\section{Effect of temperature on water desorption}

Figure 4 shows the desorption isotherms of water obtained at different temperatures with DVS and KTGA. Reasonable agreement was again obtained. In general, the changes 
Fig. 2 KTGA measurements of the desorption isotherms of volatiles from smectite clay. The mass fraction of the volatiles $w_{f}$ is plotted as a function of the volatile activity $a_{v}$ : a water at $25^{\circ} \mathrm{C}$, b water at $10{ }^{\circ} \mathrm{C}$, $\mathbf{c}$ ethanol at $10^{\circ} \mathrm{C}$, d ethyl acetate at $10^{\circ} \mathrm{C}$
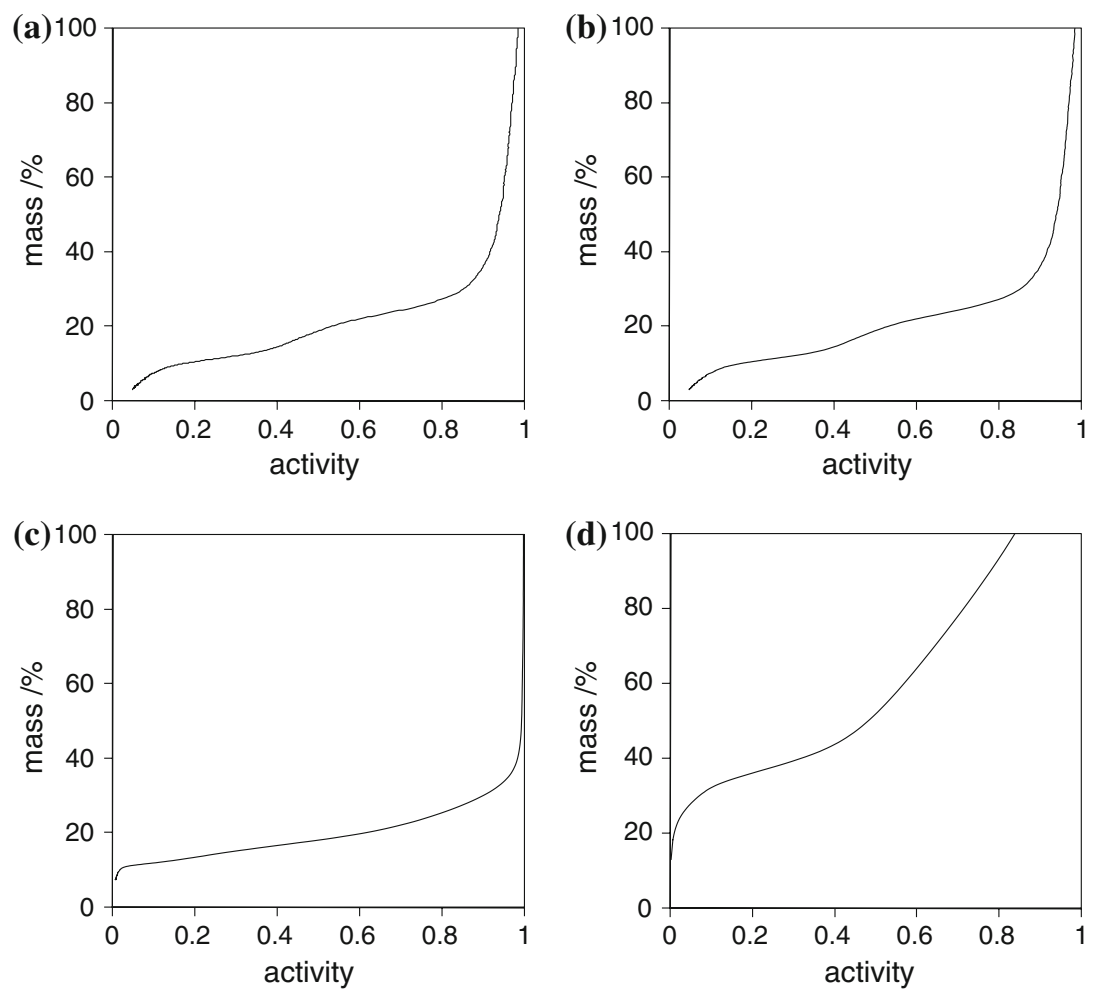

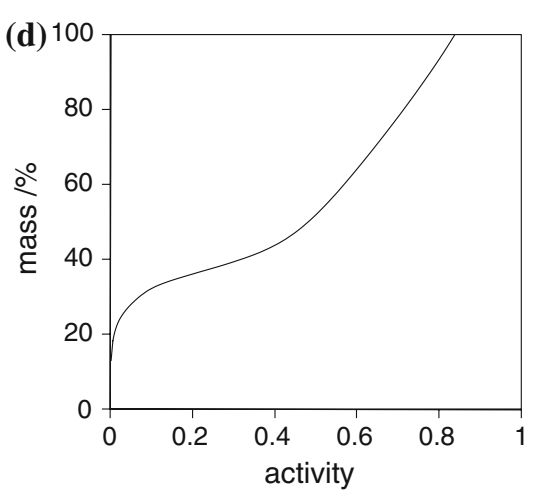

in $a_{\mathrm{w}}$ with temperature are expected to reflect the difference in binding strength between water molecules in the bulk and water molecules in the clay-water system. However, in the present case, the temperature had little effect on water desorption (at least within the experimental detection limits). The experimental results therefore suggest that the binding strength is of the same order of magnitude for the two types of interaction, which is consistent with the results of ab initio calculations [31].

In order to provide a better indication of the effect of changes of temperature on the gas/condensed phase

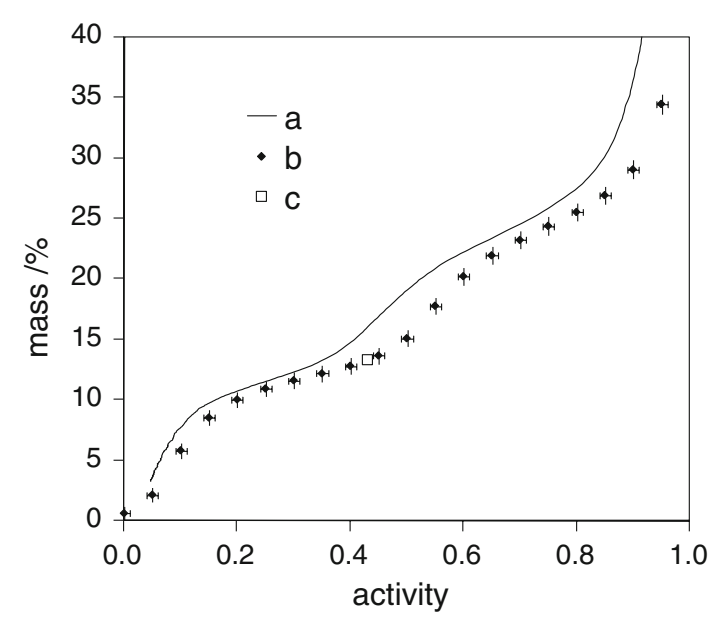

Fig. 3 Equilibrium desorption isotherms of water at $25^{\circ} \mathrm{C}: a$ KTGA method, $b$ DVS method, $c$ equilibration with saturated salt solutions partition, the same desorption data have been plotted as function of the water concentration in the gas phase, $c$, calculated according to Eq. (5), (expressed in $\mathrm{mol} \mathrm{m}^{-3}$ ), as shown in Fig. 5.

$c=\frac{p_{v}}{R T}=a_{v} \frac{p_{v}^{*}}{R T}$

At high water contents, the equilibrium concentration of water in the gas phase above the sample approaches the saturated water vapor concentration. As the water content is decreased, the water concentration in the gas phase

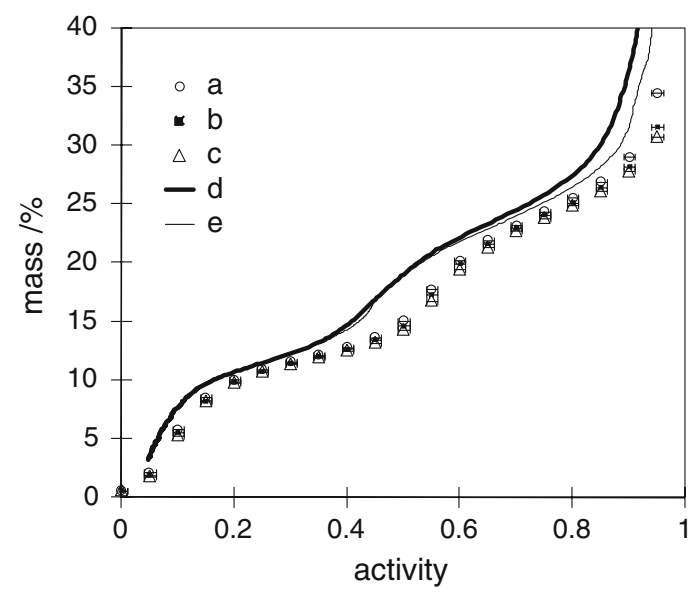

Fig. 4 Equilibrium desorption isotherm of water on the clay measured by the DVS method at $a 25^{\circ} \mathrm{C}, b 30^{\circ} \mathrm{C}$ and $c 35^{\circ} \mathrm{C}$, and by the KTGA method at $d 25^{\circ} \mathrm{C}$ and $e 10^{\circ} \mathrm{C}$ 


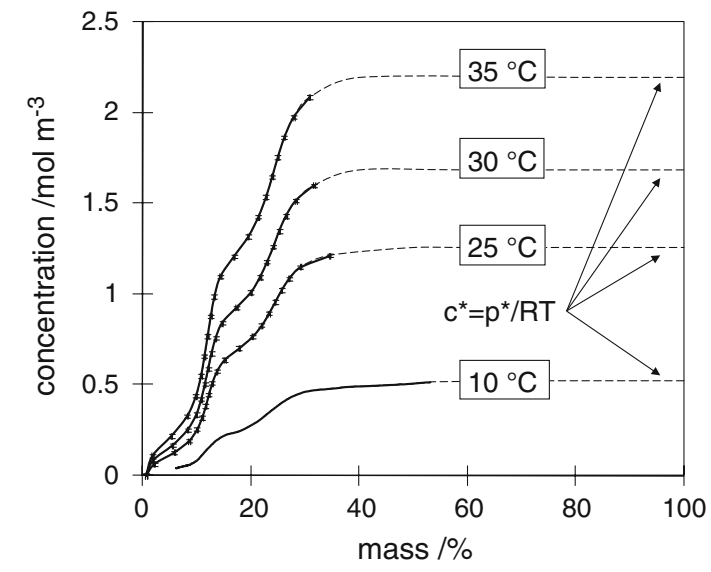

Fig. 5 Equilibrium desorption isotherm of water from smectite clay measured by DVS at $25^{\circ} \mathrm{C}, 30^{\circ} \mathrm{C}$ and $35^{\circ} \mathrm{C}$ and by KTGA method at $10^{\circ} \mathrm{C}$

decreases owing to sorption of the water molecules in the clay. There is hence a transition from a state similar to that of the bulk liquid to a state dominated by the interactions of the water molecules in the clay-water system. This transition is clearly independent of the temperature in the range considered, but decreasing the temperature decreases the gas phase concentration owing to the lower kinetic energy of the molecules.

\section{Comparison between volatiles}

To facilitate comparison of the desorption of different volatiles, the desorption data have been plotted as a function of the coverage $\theta$, defined by,

$\theta=\frac{m_{\text {solvent }}}{m_{\text {clay }}} \frac{M_{\text {clay }}}{M_{\text {solvent }}}$

where $m$ and $M$ are the mass and molar mass, respectively, the molar mass of the clay referred to one unit cell containing one sodium counter ion (746 mol/unit cell [19]). Figure $6 \mathrm{~A}-\mathrm{D}$ show the trends observed at 10 and $35^{\circ} \mathrm{C}$. At large $\theta$, all the curves attain or approach a plateau. The minimum $\theta$ at which saturation is reached with water is almost 12 molecules per unit cell, while lower values are predicted for the other volatiles. The details of the desorption at lower $\theta$, i.e. when the interaction with the clay counter ions dominates (this depends on temperature, but usually occurs at $\theta<2$ ) are shown in Fig. $6 \mathrm{C}$ and $\mathrm{D}$, for 10 and $35{ }^{\circ} \mathrm{C}$, respectively. Since one unit cell contains on average one sodium counter ion, data corresponding to $\theta<2$ reflect the interaction of the volatile molecules with the clay counter ion. The trends for the four volatiles indicate that their thermodynamic activities follow the order: ethyl acetate $>$ ethanol $>$ water $>$ toluene, according to the data at $10{ }^{\circ} \mathrm{C}$. There is more uncertainty in the
Fig. $6 \mathrm{~A}$ and $\mathbf{B}$ DVS

measurements at $35{ }^{\circ} \mathrm{C}$ of the equilibrium desorption isotherm of the volatiles on the clay. C and D KTGA measurements at $10{ }^{\circ} \mathrm{C}$ of the equilibrium desorption isotherm of the volatiles on the clay: $a$ water, $b$ ethanol, $c$ ethyl acetate and $d$ toluene
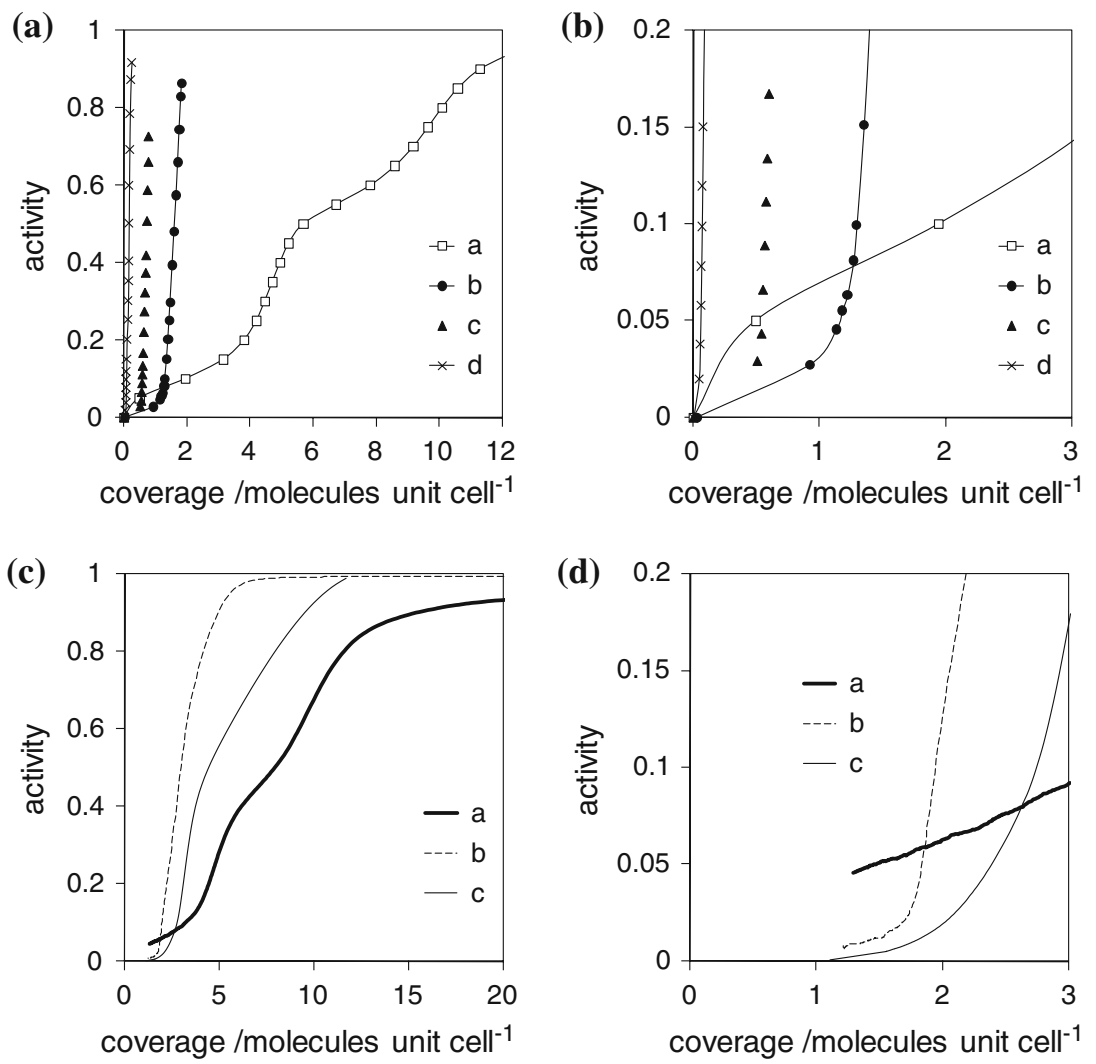

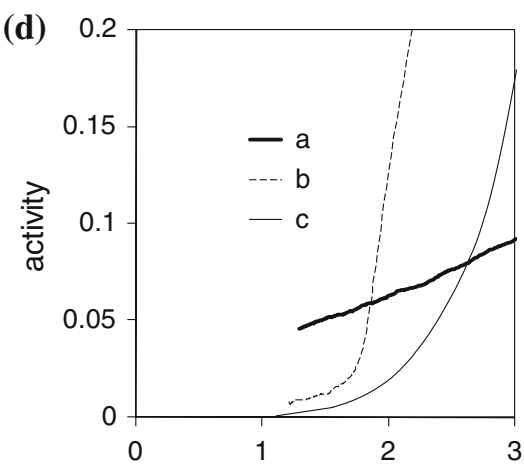

coverage /molecules unit cell ${ }^{-1}$ 
data at $35{ }^{\circ} \mathrm{C}$, because the larger volatility reduces the detectability at low $\theta$. Nonetheless, the behavior of toluene remains distinct from that of the other volatiles. This would imply an opposite ranking of the interaction strength, in so far as a larger thermodynamic activity should correspond to a weaker interaction. Further uncertainties remain for ethyl acetate. Given its lower ionization potential and its higher dipole moment ethyl acetate is expected to bind to the sodium counter ion more strongly than ethanol. This is consistent with the results of ab initio calculations of the binding of the single volatile molecules to the sodium counter ion [31].
In a previous paper, we used the equilibrium desorption isotherm of water to calculate the rate of release of water from the sodium clay [19]. The link between this equilibrium property and the release kinetics can be qualitatively understood by Fick's second law, which relates the flux of molecules leaving the adsorbent to the concentration gradient between the surface concentration $c$ and the far field concentration. Figure 7A-D show the equilibrium desorption isotherms plotted in terms of plane $c$ and $\theta$. The plateau attained at high coverage is related to the vapour pressure of the pure volatile (see Eq. 5) $p_{v}^{*}$, that can be calculated (see Table 1) with the Antoine equation (Eq. 7),

\section{Fig. $7 \mathrm{~A}$ and $\mathbf{B}$ DVS}

measurements at $35{ }^{\circ} \mathrm{C}$ of the equilibrium desorption isotherm of the volatiles on the clay; C and D KTGA measurements at $10{ }^{\circ} \mathrm{C}$ of the equilibrium desorption isotherm of the volatiles on the clay: $a$ water, $b$ ethanol, $c$ ethyl acetate and $d$ toluene
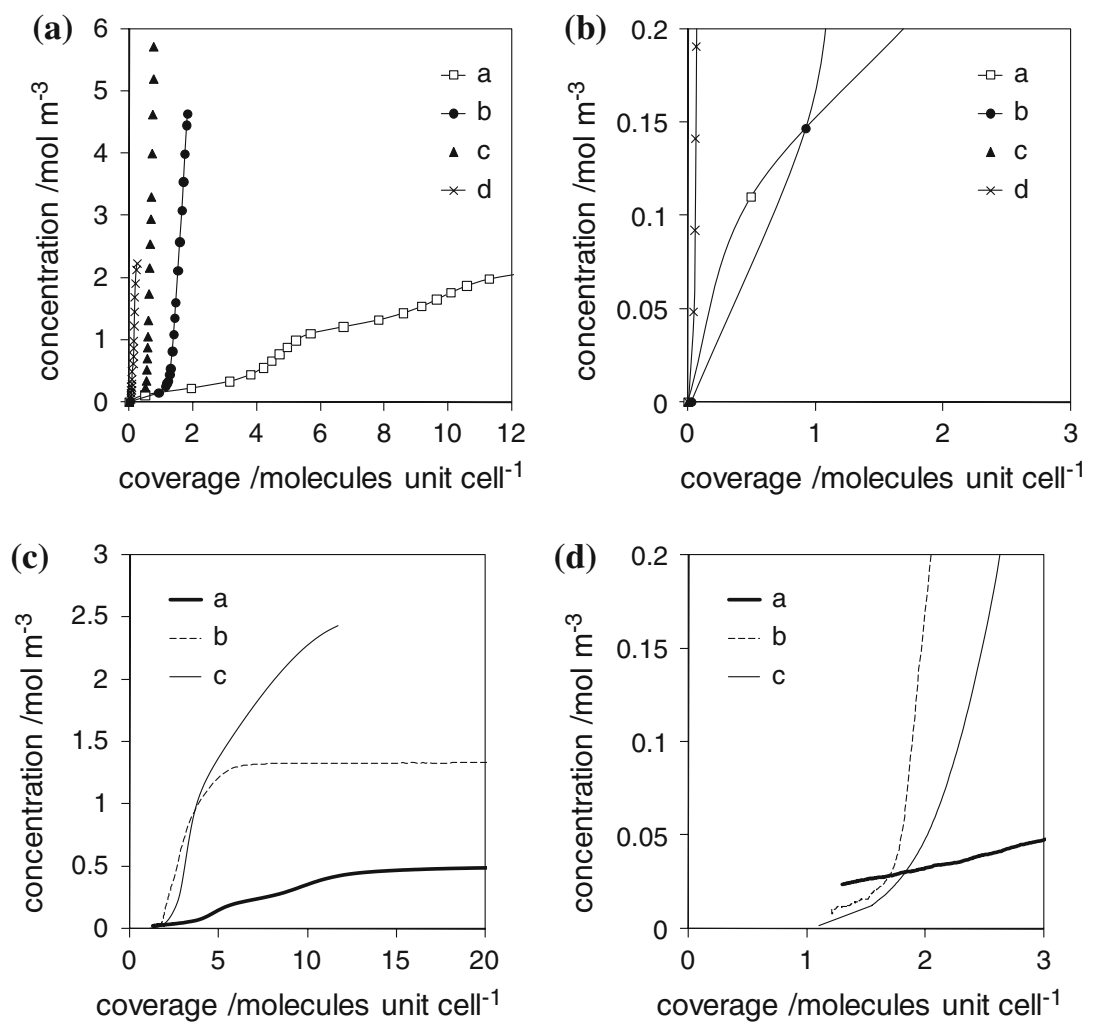

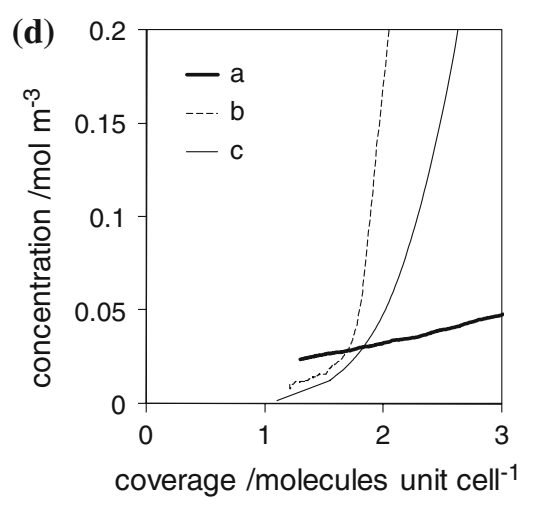

Table 1 Saturated vapor pressures $p^{*}$ calculated with the Antoine equation, and corresponding saturated gas concentration $c^{*}$ at various temperatures $T$

\begin{tabular}{llcl}
\hline Volatile & Temperature $\left({ }^{\circ} \mathrm{C}\right)$ & Saturated vapour pressure $(\mathrm{Pa})$ & Saturated vapour concentration $\left(\mathrm{mol} \mathrm{m}^{-3}\right)$ \\
\hline Water & 35 & 3167 & 2.20 \\
& 25 & 5624 & 2.27 \\
& 10 & 1227 & 0.52 \\
Ethanol & 35 & 13757 & 5.37 \\
& 10 & 3141 & 1.33 \\
Ethyl acetate & 35 & 20119 & 7.85 \\
& 10 & 5802 & 2.46 \\
Toluene & 35 & 6239 & 2.44 \\
\hline
\end{tabular}


taking values of the constants $\mathrm{A}, \mathrm{B}$, and $\mathrm{C}$ drawn from literature [33-37] for each volatile. At high coverage the gas phase concentrations follow therefore the order: ethyl acetate $>$ ethanol $>$ toluene $>$ water. At $\theta<2$ (Fig. 7B and $\mathrm{D}$ ), the ranking order of $c$ is the same as for the corresponding $a_{\mathrm{v}}$ (see Fig. $6 \mathrm{~B}$ and D, which not necessarily true for any given set of volatiles since, from Eq. 5, different $p^{*}$ can lead to different ranking of $c$ (see Table 1).

$\log _{10}\left(p_{v}^{*}\right)=A-\frac{B}{C+T}$

\section{Conclusions}

Dynamic vapour sorption (DVS) measurements and Knudsen thermogravimetry (KTGA) yield very similar shapes for the desorption isotherm of water from clay at $25{ }^{\circ} \mathrm{C}$, with a maximal variation of $2.5 \% \mathrm{RH}$. These results support the substantial complementary of the two methods and justify their use to compare the behaviour of other volatiles, namely, ethanol, ethyl acetate and toluene, which were compatible with either approach.

The relevant results allowed the following conclusions:

- at high coverage the desorption behaviour observed reflects the bulk properties and the different volatilities of the four volatiles;

- at low coverage $(\theta<2)$, where the prevailing process is the interaction with the sodium counter ions of the clay, the desorption trends allow ranking the volatiles according to the relevant strength of interaction, namely, ethyl acetate $>$ ethanol $>$ water $>$ toluene.

These conclusions are in agreement with previous ab initio calculations and are useful for further exploitation of the smectite clays applications.

Acknowledgements This study was supported financially by the Nestlé Research Center (NESTEC, Switzerland).

\section{References}

1. Murray HH. Traditional and new applications for kaolin, smectite, and palygorskite: a general overview. Appl Clay Sci. 2000;17: 207-21.

2. Norrish K. The swelling of montmorillonite. Discuss Faraday Soc. 1954;18:120-34.

3. Hensen EJM, Smit B. Why clay swell. J Phys Chem B. 2002; 106:12664-7.

4. Zhang F, Low PF, Roth CB. Effects of monovalent, exchangeable cations and electrolytes on the relation between swelling pressure and interlayer distance in montmorillonite. J Colloid Interface Sci. 1995; 173:34-41.

5. McBride MB, Baveye P. Diffuse double-layer models, long-range forces, and ordering in clay colloids. Soil Sci Soc Am J. 2002;66: 1207-17.
6. Mooney RW, Keenan AG, Wood LA. Adsorption of water vapor by montmorillonite. II. Effect of exchangeable ions and lattice swelling as measured by X-ray diffraction. J Am Chem Soc. 1952;74:1371-4.

7. Sposito G, Prost R. Structure of water adsorbed on smectites. Chem Rev. 1982;82:553-73.

8. Stul MS, Uytterhoeven JB. Interlamellar sorption of ethanol on montmorillonite clays with different layer charges. J Chem Soc, Faraday Trans. 1975;1:1396-1401.

9. Cosultchi A, Bosch P, Lara VH. Adsorption of petroleum organic compounds on natural wyoming montmorillonite. Colloids Surf A. 2004;243:53-61.

10. Bissada KK, Johns WDCFS. Cation-dipole interactions in clay organic complexes. Clay Miner. 1967;7:155-66.

11. Hiltabrand RR. Montmorillonite-organic complexes: bonding energies associated with ion extraction. Modern Geol. 1971;2:49-54.

12. Zhu D, Herbert BE, Schlautman MA, Carraway ER, Hur J. Cationpi bonding: a new perspective on the sorption of polycyclic aromatic hydrocarbons to mineral surfaces. J Environ Qual. 2004;33: 1322-30.

13. Ovadyahu D, Yariv S, Lapides I, Deutsch Y. Mechanochemical adsorption of phenol by TOT swelling clay minerals. II. Simultaneous DTA and TG study. J Therm Anal. 1998;51:431-47.

14. Burstein F, Borisover M, Lapides I, Yariv S. Secondary adsorption of nitrobenzene and $\mathrm{m}$-nitrophenol by hexadecyltremethylammoniummontmorillonite thermo-XRD-analysis. J Therm Anal Calorim. 2007;92:35-42.

15. Li H, Teppen BJ, Johnston CT, Boyd SA. Thermodynamics of nitroaromatic compound adsorption from water by smectite clay. Environ Sci Technol. 2004;38:5433-42.

16. Alexandre M. Polymer-layered silicate nanocomposites: preparation, properties and uses of a new class of materials. Mater Sci Eng. 2000;28:1-63.

17. Simpson AJ, Simpson MJ, Kingery WL, Lefebvre BA, Moser A, Williams AJ, et al. The application of $1 \mathrm{H}$ high-resolution magicangle spinning NMR for the study of clay-organic associations in natural and synthetic complexes. Langmuir. 2006;22:4498-503.

18. Souza CEC, Nascimento RSV. Adsorption behaviour of cationic polymers on bentonite. J Therm Anal Calorim. 2008;94:579-83.

19. Clausen P, Watzke B, Hughes E, Plummer JGC, Månson EJA. Evaporation kinetics of volatile liquids and release kinetics of water from a smectite clay: comparison between experiments and finite element calculations. Int J Eng Sci. 2008 (in review).

20. Tambach TJ, Bohuis PG, Hensen JM, Smit B. Hysteresis in clay swelling induced by hydrogen bonding: accurate pediction of swelling states. Langmuir. 2006;22:1223-34.

21. Bérend I, Cases J-M, Francois M, Uriot J-P, Michot LJ, Maison A, et al. Mechanism of adsorption and desorption of water vapor by homoionic montmorillonites: $2 \mathrm{The}^{+}{ }^{+}, \mathrm{Na}^{+}, \mathrm{K}^{+}, \mathrm{Rb}^{+}$, and $\mathrm{Cs}^{+}$-exchanged forms. Clays Clay Miner. 1995;43:324-36.

22. Fowler RH. A statistical derivation of Langmuir's adsorption isotherm. Proc Cambridge Phil Soc. 1935;31:260-4.

23. Brunauer S, Emmett PH, Teller E. Adsorption of gases in multimolecular layers. J Am Chem Soc. 1938;60:309-19.

24. Timmermann EO. A B.E.T.-like three sorption stage isotherm. J Chem Soc Faraday Trans. 1989;85:1631-45.

25. Khalfaoui M, Knani S, Hachicha MA, Lamine AB. New theoretical expressions for the five adsorption type isotherms calssified by BET based on statistical physics treatment. J Colloid Interface Sci. 2003;263:350-6.

26. Ayappa KG, Kamala CR, Abinandanan TA. Mean field lattice model for adsorption isotherms in zeolite NaA. J Chem Phys. 1999;110:8714-20.

27. Bissada KK, Johns WD. Montmorillonite-organic complexesgas chromatographic determination of energies of interactions. Clays Clay Miner. 1969;17:197-204. 
28. Xiong JC, Maciel GE. Deuterium NMR studies of local motions of benzene adsorbed on Ca-montmorillonite. J Phys Chem B. 1999;103:5543-9.

29. Ovadyahu D, Yariv S, Lapides I. Mechanochemical adsorption of phenol by TOT swelling clay minerals. I. Thermo-IR-spectroscopy and X-ray study. J Therm Anal. 1998;51:415-30.

30. Lide DR. Handbook of chemistry and physics. 75 th ed. Boca Raton: CRC Press; 1994

31. Clausen P, Andreoni W, Curioni A, Hughes E. Adsorption of lowmolecular weight molecules on a dry clay surface: an ab initio study. J Phys Chem. 2008 (in press).

32. Schiraldi A, Fessas D. Classical and Knudsen thermogravimetry to check states and displacements of water in food systems. J Therm Anal Calorim. 2003;71:221-31.
33. Bridgeman OC, Aldrich EW. Vapor pressure tables for water. J Heat Transf. 1964;86:279-86.

34. Kretschmer CB, Wiebe R. Liquid-vapor equilibrium of ethanoltoluene solutions. J Am Chem Soc. 1949;71:1793-7.

35. Ambrose D, Sprake CHS. Thermodynamic properties of organic oxygen compounds. XXV. Vapor pressures and normal boiling temperatures of aliphatic alcohols. J Chem Thermodyn. 1970;2: 631-45.

36. Polak J, Mertl I. Saturated vapour pressure of methyl acetate, ethyl acetate, n-propyl acetate, methyl propionate, and ethyl propionate. Collect Czech Chem Commun. 1965;30:3526-8.

37. Besley LM, Bottomley GA. Vapour pressure of toluene from 273.15 to 298.15 K. J Chem Thermodyn. 1974;6:577-80. 